\title{
A REVIEW ON RHEOLOGY OF NON-NEWTONIAN PROPERTIES OF BLOOD
}

\author{
ESMAEel FATAHIAN ${ }^{*}$, NASER KORdANI ${ }^{2}$ AND Hossein FATAHIAN ${ }^{1}$ \\ ${ }^{I}$ Department of Mechanical Engineering, Nour Branch, \\ Islamic Azad University, Nour, Iran. \\ ${ }^{2}$ Department of Mechanical Engineering, University of Mazandaran, \\ Mazandaran, Iran. \\ *Corresponding author: esmaeelfatahian@gmail.com
}

(Received: $5^{\text {th }}$ March 2017; Accepted: 22 $2^{\text {nd }}$ May 2017; Published on-line: $1^{\text {st }}$ June 2018)

https://doi.org/10.31436/iiumej.v19i1.826

\begin{abstract}
Human blood is composed of red cells, white blood cells, and platelets in a fluid called plasma that contains organic and mineral salts and protein. The rheological characteristics of blood are determined by the properties of these combinations and their interaction with each other. The plasma is essentially a Newtonian fluid, but the blood as a whole behaves as a non-Newtonian fluid showing all signs of non-Newtonian rheology including deformation rate dependency, viscoelasticity, yield stress, and thixotropy. The purpose of this study is mainly a review based on past work on blood rheology, determinants of blood viscosity, yield stress, thixotropy, blood viscosity measurement, and heat transfer in blood flow to better understand the non-Newtonian effect in the blood circulation system.
\end{abstract}

ABSTRAK: Darah manusia terdiri daripada sel-sel merah, sel darah putih dan platlet dalam cecair yang dipanggil plasma, mengandungi garam organik dan mineral dan protein. Ciri-ciri sifat reologi darah ditentukan oleh sifat-sifat kombinasi ini dan interaksi antara satu sama lain. Plasma adalah pada dasarnya Newtonian cecair tetapi secara keseluruhannya darah bersifat sebagai bukan suatu cecair Newtonian yang menunjukkan tanda-tanda bukan Newtonian reologi, mengandungi pergantungan kadar ubah bentuk, kelikatkenyalan, tegasan alah dan thixotropi. Tujuan kajian ini adalah berkenaan ulasan kajian-kajian lepas berkaitan rheology darah, penentu viskositi darah, tegasan alah dan thixotropi, ukuran kelikatan darah dan pemindahan haba dalam aliran darah bagi memahami kesan bukan Newtonian dalam sistem peredaran darah.

KEYWORDS: blood rheology; non-Newtonian fluids; shear-thinning behavior; thixotropy

\section{INTRODUCTION}

A non-Newtonian fluid is a fluid with properties that are different in any way from those of Newtonian fluids. Most commonly, the viscosity (the measure of a fluid's ability to resist gradual deformation by shear or tensile stresses) of non-Newtonian fluids is dependent on the shear rate or shear rate history. Some non-Newtonian fluids with shearindependent viscosity, however, still exhibit normal stress-differences or other nonNewtonian behavior. Many salt solutions and molten polymers are non-Newtonian fluids, as are many commonly found substances such as ketchup, custard, toothpaste, starch suspensions, (STF)/fabric composites, maizena, paint, blood, and shampoo [1, 2]. Blood is a complex fluid with non-Newtonian characteristics, it has a shear-thinning behavior [3] and often exhibits a yield stress (viscoplasticity) [4-6] with potential history effects 
(thixotropy) [7]. The rheological complexity of blood is attributed to its constituents. Rheologically, blood is primarily characterized as a concentrated suspension of elastic, deformable red blood cells (RBCs). However, it also contains other ingredients such as leukocytes and platelets within plasma. Yield stress is an important characteristic of blood rheology and an essential component of its non-Newtonian nature. Experimental evidence for its association with blood has been provided in many investigations [8,9] and with different experimental techniques, as described by Picard et al. [10]. From a modeling point of view, the role of yield stress is most clearly evaluated under steady-state shear flow conditions. As a shear, thinning fluid, blood is also characterized by a thixotropic behavior, which is confirmed experimentally by a number of studies [11], due to the intimate relation between these two non-Newtonian properties [12]. This may also explain a possible controversy about the thixotropic nature of blood [13] as the thixotropic-like behavior may be explained by other non-Newtonian characteristics of blood. Despite the fact that thixotropy is a transient property, due to the pulsative nature of the blood flow, the thixotropic effects may have long term impact on blood circulation. This equally applies to the time-dependent effects of viscoelasticity. Thixotropy is more pronounced at low shear rates with a long-time scale. The effect, however, seems to have a less important role in blood than other non-Newtonian effects such as shear thinning [14], and this could partly explain the limited amount of studies dedicated to this property. The thixotropic behavior of blood is very sensitive to blood composition and hence it can demonstrate big variations between different individuals and under different biological conditions [11]. Blood is an important fluid in the human body therefore, measuring the viscosity and other properties can be used in the diagnosis of various cardiovascular system diseases. Measuring viscosity is an important property of blood requiring the use of the right tools. Different tools are used to measure blood viscosity including capillary tube viscometers, cone and plate viscometers, concentric cylinder viscometers, rotating disc viscometers and acoustic wave viscometers. The body's internal heat transfer is controlled by the blood circulatory system. The blood circulatory system reduces the temperature differences in the body. The most important applications of modeling heat transfer in the body can be noted in surgery (especially open-heart surgery), dialysis devices, and also in the making of artificial blood vessels. The current study, which is basically a brief overview of the rheological properties of blood, is trying to explain the rheological behavior of blood and discuss the four main determinants of whole blood viscosity. We consider the yield stress and thixotropy behaviour that describe the blood rheology and finally investigate heat transfer in blood.

\section{RHEOLOGY OF BLOOD}

Blood behaves like a non-Newtonian fluid whose viscosity varies with shear rate. The non-Newtonian characteristics of blood come from the presence of various cells in the blood (typically making up 45\% of the blood's volume) that make blood a suspension of particles $[15,16]$. When the blood begins to move, these particles (or cells) interact with plasma and among themselves. Hemorheologic parameters of blood include whole blood viscosity, plasma viscosity, red cell aggregation, and red cell deformability (or rigidity). From a biological point of view, blood can be considered as a tissue comprising various types of cells (i.e., RBCs, WBCs, and platelets) and a liquid intercellular material (i.e., plasma). From a rheological point of view, blood can be thought of as a two-phase liquid; it can also be considered as a solid-liquid suspension, with the cellular elements being the solid phase. However, blood can also be considered as a liquid-liquid emulsion based on the liquid-like behavior of RBCs under shear. 


\section{DETERMINANTS OF BLOOD VISCOSITY}

Much research has been performed to formulate a theory that completely accounts for the viscous properties of blood, and some of the key determinants have been identified $[17,18]$. The four main determinants of whole blood viscosity are (1) plasma viscosity, (2) hematocrit, (3) RBC deformability and aggregation, and (4) temperature. The first three factors are parameters of physiological concern because they pertain to changes in whole blood viscosity in the body. The second and third factors, hematocrit and RBC (red blood cells) aggregations, are the main contributors to the non-Newtonian characteristics of shear-thinning viscosity and yield stress.

\section{YIELD STRESS}

In addition to non-Newtonian viscosity, blood also exhibits a yield stress. The source of the yield stress is the presence of cells in the blood, particularly red cells. When such a huge amount (40-45\% by volume) of red cells of 8-10 microns in diameter is suspended in plasma, cohesive forces among the cells are not negligible. The forces existing between particles are van der Waals-London forces and Coulombic forces [19, 20]. Hence, in order to initiate a flow from rest, one needs to have a force that is large enough to break up the particle-particle links among the cells. However, blood contains $40-45 \%$ red cells and still moves relatively easily. The healthy red cells behave like liquid drops because the membranes of red cells are so elastic and flexible. Note that in a fluid with no suspended particles, the fluid starts to move as soon as an infinitesimally small amount of force is applied. Such a fluid is called a fluid without yield stress. Examples of fluid with no yield stress include water, air, mineral oils, and vegetable oils. Examples of fluids having yield stress include blood, ketchup, salad dressings, grease, paint, and cosmetic liquids. The magnitude of the yield stress of human blood appears to be at the order of $0.05 \mathrm{dyne} / \mathrm{cm}^{2}$ (or $5 \mathrm{mPa}$ ) [21,22] and is almost independent of temperature in the range of $10-37^{\circ} \mathrm{C} \mathrm{[23].}$ Blood shows a Newtonian fluid's character when it flows through larger diameter arteries at high shear rates, but it exhibits a remarkable non-Newtonian behavior when it flows through small diameter arteries at low shear rates [24, 25]. Moreover, there is an increase in viscosity of blood at low rates of shear as the red blood cells tend to aggregate into the Rouleaux form [26]. Rouleaux form behaves as a semi-solid along the center forming a plug flow region. In the plug flow region, we have a flattened parabolic velocity profile rather than the parabolic velocity profile of a Newtonian fluid. This behavior can be modeled by the concept of yield stress. The yield stress for blood depends strongly on fibrinogen concentration and is also dependent on the hematocrit. The yield stress values for normal human blood is between 0.01 and $0.06 \mathrm{dyne} / \mathrm{cm}^{2}$ [27]. The Casson fluid model is a non-Newtonian fluid with yield stress, which is widely used for modeling blood flow in narrow arteries. Many researchers have used the Casson fluid model for mathematical modeling of blood flow in narrow arteries at low shear rates. It has been demonstrated by Blair [28] and Copley [29] that the Casson fluid model is adequate for the representation of the simple shear behavior of blood in narrow arteries. Casson examined the validity of the Casson fluid model in his studies pertaining to the flow characteristics of blood and reported that at low shear rates, the yield stress for blood is nonzero [30]. Venkatesan et al. investigated the flow of blood through a narrow artery with bell-shaped stenosis, treating blood as Casson fluid. Results are compared with the results of the Herschel Bulkley fluid model obtained by Misra and Shit for the same geometry [31]. Resistance to flow and skin friction are normalized in two different ways such that (i) with respect to the same nonNewtonian fluid in a normal artery, it gives the effect of a stenosis and (ii) with respect to the Newtonian fluid in the stenosed artery, it spells out the non-Newtonian effects of the 
fluid. It is found that the resistance to flow and skin friction increase with the increase of maximum depth of the stenosis, but these flow quantities (when normalized with nonNewtonian fluid in normal artery) decrease with the increase of the yield stress, as obtained by Misra and Shit [31]. It is also noticed that the resistance to flow and skin friction increase (when normalized with Newtonian fluid in stenosed artery) with the increase of the yield stress [32]. Yield stress arises from the aggregation of red blood cells at low shear rates to form the three-dimensional micro-structures (Rouleaux) that resist the flow [33-35]. Studies have indicated that yield stress is positively correlated to the concentration of fibrinogen protein in blood plasma and to the hematocrit level $[36,37]$. Other factors, such as the concentration of minerals, should also have a contribution. Many of the blood rheological characteristics in general, and non-Newtonian in particular, are also controlled or influenced by the fibrinogen level [35]. The yield stress characteristic of blood seems to vanish or become negligible when hematocrit level falls below a critical value [36]. Yield stress contributes to the blood clotting following injuries and subsequent healing, and may also contribute to the formation of blood clots (thrombosis) and vessel blockage in some pathological cases such as strokes. The magnitude of yield stress and its effect could be aggravated by certain diseased states related to the rheology of blood, like polycythemia vera, or the structure of blood vessels such as stenosis. Dependence of yield stress of human blood on hematocrit level on a loglinear plot is shown in Fig. 1. Other types of correlation have also been obtained in other studies $[38,39]$.

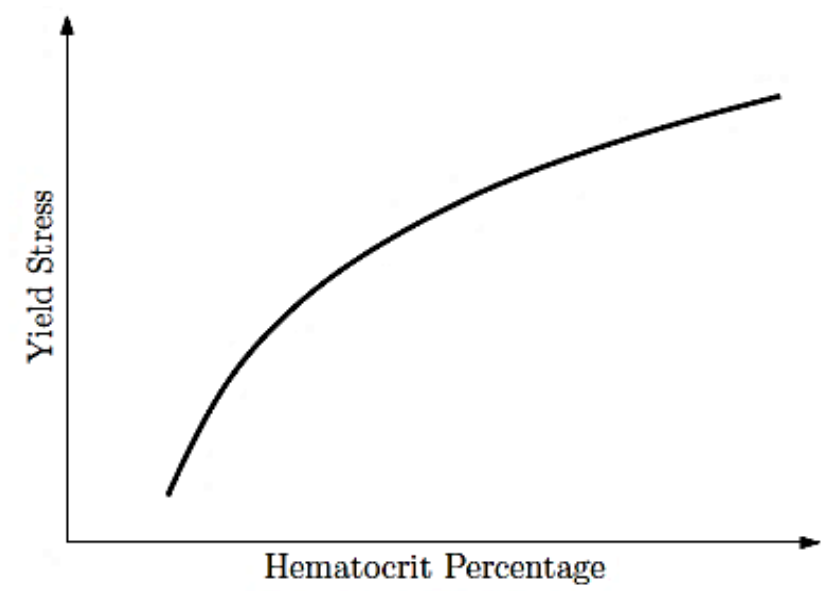

Fig. 1: Dependence of yield stress of human blood on hematocrit level on a log-linear plot $[38,39]$.

\section{THIXOTROPY}

The phenomenon of thixotropy in a liquid result from the microstructure of the liquid system. Thixotropy may be explained as a consequence of aggregation of suspended particles. If the suspension is at rest, the particle aggregation can form, whereas if the suspension is sheared, the weak physical bonds among particles are ruptured, and the network among them breaks down into separate aggregates that can disintegrate further into smaller fragments [40]. After some time at a given shear rate, a dynamic equilibrium is established between aggregate destruction and growth, and at higher shear rates, the equilibrium is shifted in the direction of greater dispersion. The relatively long time required for the microstructure to stabilize following a rapid change in the rate of flow makes blood thixotropy readily observable [41]. This effect on viscosity has been studied 
using a steady flow [42]. At high shear rates, structural change occurs more rapidly than at low shear rates. Huang et al. [42] investigated the first step for a no-flow condition to a shear rate of $10 \mathrm{~s}^{-1}$. They found that blood viscosity decreased over a period of approximately 20 seconds at the shear rate of $10 \mathrm{~s}^{-1}$ before the final state was attained. Next, when the shear rate stepped up from 10 to $100 \mathrm{~s}^{-1}$, almost no time was required to reach the microstructural equilibrium after the change of shear rate. Gaspar-Rosas and Thurston also investigated erythrocyte aggregate rheology by varying the shear rate from $500 \mathrm{~s}^{-1}$ to zero [43]. Based on their results, it can be concluded that the recovery of the quiescent structure requires approximately 50 seconds while the high shear rate structure is attained in a few seconds. In other words, in order to minimize the effect of the thixotropic characteristic of blood on the viscosity measurement between the shear rates of 500 and $1 \mathrm{~s}^{-1}$, at least 50 seconds should be allowed during the test to have the fully aggregated quiescent state at a shear rate near $1 \mathrm{~s}^{-1}$.

\section{BLOOD VISCOSITY MEASUREMENT}

Blood viscosity is an important property for the regulation of rheological conditions because it produces resistance to fluid deformations. Blood viscosity is mainly determined by the hematocrit and varies with the shear rate as a non-Newtonian fluid [44, 45]. Blood viscosity is important for understanding physiological blood flow conditions [46, 47]. Numerous types of rheometers have been used to measure the viscosity and yield stress of materials [48-50]. Typically, shear viscometers can be divided into two groups: drag flows, in which shear is generated between a moving and a stationary solid surface, and pressure-driven flows, in which shear is generated by a pressure difference over a capillary tube [50]. The commonly utilized members of these groups are shown in Fig. 2. Among the several types of viscometers currently available, rotational viscometers have mainly been used to measure whole blood viscosity because they measure viscosity within a certain shear rate range with a relatively small amount of sample [51].

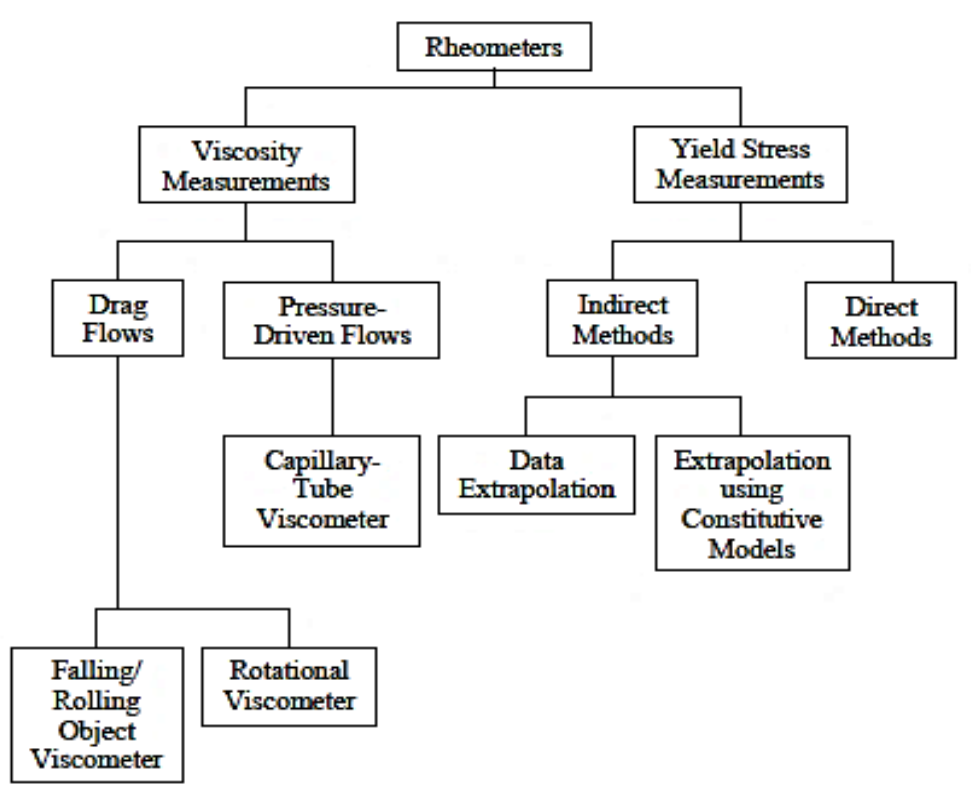

Fig. 2: Rheometers [50]. 
Shin et al. developed a pressure-scanning capillary viscometer that used a pressure transducer to measure the viscosity of non-Newtonian fluids including blood [52]. Shin et al. also developed a blood hemorheometer, featuring a vacuum suction-type pressure scanning mechanism, that has been successfully employed to detect the mechanical behavior of red blood cell aggregation [53]. Lee et al. [54] studied the applicability of two non-Newtonian constitutive models (Casson and Herschel-Bulkley models) in the determination of the blood viscosity and yield stress using a pressure-scanning microfluidic hemorheometer. The present results were compared with the measurements through a precision rheometer (ARES2). For a Newtonian fluid (standard oil), the two constitutive models showed excellent agreement with a reference value and the measurement of ARES2. For human blood as a non-Newtonian fluid, both the Casson and Herschel-Bulkley models exhibited similar viscosity results over a range of shear rates and showed excellent agreement with the ARES2 results. The Herschel-Bulkley model yielded a slightly higher value than other results at low shear rates $(\dot{Y}<10)$, which may be due to the relatively high value of the yield stress. The yield stress values for whole blood were $14.4 \mathrm{mPa}$ for the Casson model and $32.5 \mathrm{mPa}$ for the Herschel-Bulkley model, respectively. Thus, their study showed that the Casson model would be better than the Herschel-Bulkley model for representing the non-Newtonian characteristics of blood viscosity [54]. Kang et al. [55] proposed a unique microfluidic device for simultaneously measuring viscosity and flow rate of whole blood circulating in a complex fluidic network. Based on the microfluidic device, three sequential flow controls were applied to identify viscosity and flow rate of blood, with label-free and sensor-less detection. To quantify the effect of flow stabilization on flow fluctuations, a formula for the pulsation index (PI) was analytically derived using a discrete fluidic circuit model. Using the PI formula, the time constant contributed by the half-circular chamber is estimated to be $8 \mathrm{~s}$. Furthermore, flow fluctuations resulting from the peristaltic pumps are completely removed, especially under periodic flow conditions. The result showed that the flow rate and viscosity of blood can be simultaneously measured with satisfactory accuracy. In addition, the proposed method was successfully applied to identify the viscosity of rat blood, which circulates in a complex fluidic network. These observations confirm that the proposed method can be used for simultaneous measurement of viscosity and flow rate of whole blood circulating in the complex fluid network, with sensor-less and label-free detection. Furthermore, the proposed method will be used in evaluating variations in the viscosity of human blood during cardiopulmonary bypass procedures or hemodialysis [55]. Kang et al. presented the first experimental work on the viscosity measurement of adult zebrafish whole blood using a capillary pressure-driven microfluidic viscometer. After the device calibration with water, the viscosity measurement of human whole blood was performed and in good agreement with published data, demonstrating the reliability of the device. Power law and Carreau-Yasuda rheological models were used to model the non-Newtonian behaviors of the human and zebrafish blood [56]. The viscosity measurement of adult zebrafish whole blood is shown in Fig. 3. Furukawa applied an electromagnetic spinning sphere (EMS) viscometer to the measurement of human blood viscosity for the first time. They collected blood samples from 100 healthy outpatient volunteers in order to analyze viscosity dependence on blood cell parameters and on the shear rate. This study demonstrated a strong exponential correlation between the hematocrit and blood viscosity. However, the total count of RBC and platelets correlated more strongly with blood viscosity than the hematocrit. This result indicates that blood viscosity is likely to be more affected by blood cell particle numbers than by blood cell volume. Although this comparison has not been addressed in human clinical studies, a previous animal study demonstrated that the blood cell count had a stronger influence on blood viscosity than the hematocrit [57]. This study 
also performed a comparison of hematological and rheological parameters between rats and dogs. Although no significant differences were observed in the hematocrit between rats and dogs, blood viscosity and the RBC count were significantly greater in rats than in dogs. Finally, this study revealed that its dependence on blood cell parameters varied with the shear rate, while its dependence on the shear rate varied with individual differences, suggesting that actual individual measurements are important for the assessment of blood viscosity. Based on this necessity, the EMS viscometer has a high degree of usability to measure blood viscosity because of its advantageous measurement characteristics, including less blood contamination, less blood sedimentation and the minimal requirement of a sample volume of only $0.3 \mathrm{ml}$. Therefore, the measurement of blood viscosity with the EMS viscometer appears to be promising for understanding the hemodynamic-related pathogenesis of vascular diseases [58].
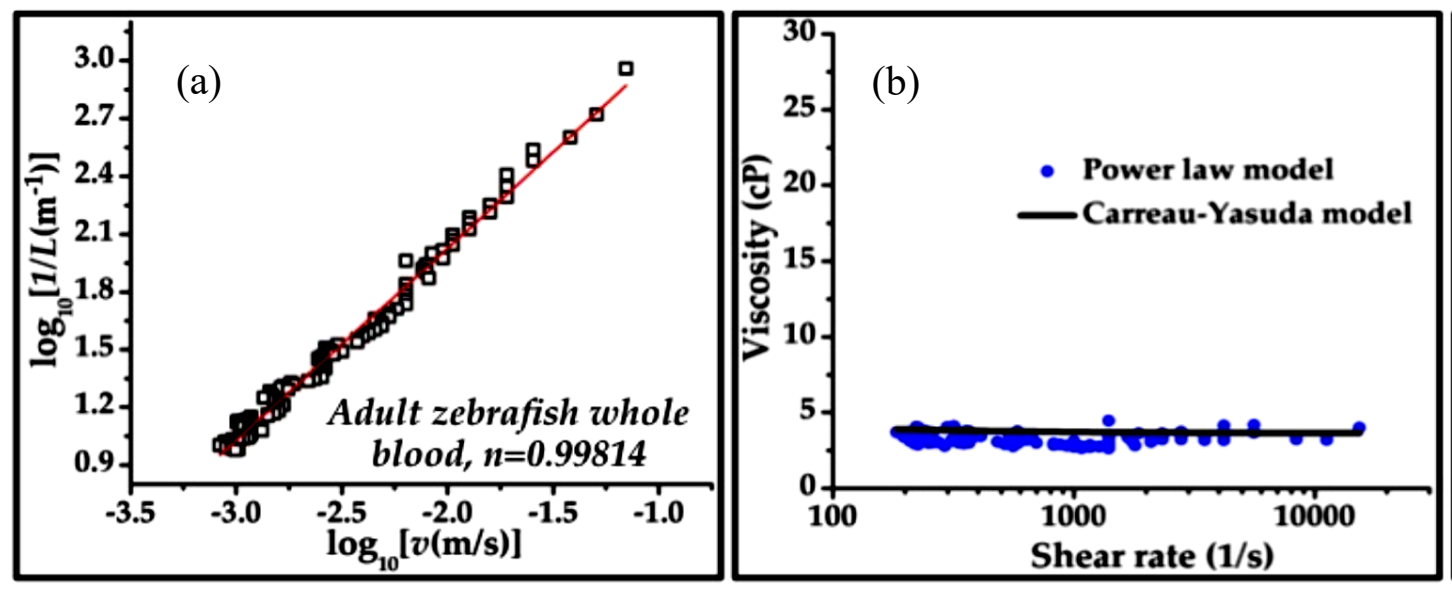

Fig. 3: The viscosity measurement of unadulterated adult zebrafish whole blood at $20{ }^{\circ} \mathrm{C}$. (a) $\mathrm{n}=0.99814$. (b) Shear rates range from $184.2 \mathrm{~s}^{-1}$ to $15399.9 \mathrm{~s}^{-1}[56]$.

\section{HEAT TRANSFER OF BLOOD FLOW}

Internal heat transfer of body is controlled by the blood circulatory system. Blood circulatory system reduces the temperature differences in body. The most important applications of modeling heat transfer in the body can be noted in surgery (especially open-heart surgery), dialysis devices, and also making artificial blood vessels. In 1948, Pennes investigated the thermal conductivity in human body tissue and the effects of blood flow on the temperature of tissue. According to his model, mass transfer rate between blood and adequate tissue was the difference between the amount of a substance in the tissue and blood multiplied by the intensity of blood flow. So, when the heat transferred from the blood to the tissues' temperature, differences between the arterial blood into the tissues and venous blood coming out of it were adequate [59]. Here, we present a simplified model of the bioheat equation for steady-state, one-dimensional heat transfer. From a one-dimensional energy balance in the $\mathrm{x}$-direction:

$$
d^{2} T / d x^{2}+\left(q_{m}+q_{p}\right) /_{k}=0
$$

where $q_{m}$ is the metabolic heat source term and $q_{p}$ is the perfusion heat source term, both per unit volume and the thermal conductivity, $k$, is a constant. Pennes [60] proposed an expression for the perfusion term by assuming that the temperatures of blood entering and exiting capillaries are both constant for any small volume of tissue. We can say that the 
temperatures of the blood at each state are the same as that of the surroundings, namely the arterial temperature and the local tissue temperature. Now the perfusion rate, $W$, must be defined. This is the ratio of the volumetric flow rate of blood per volume of tissue. Thus, we have for the perfusion term:

$$
q_{p}=W \rho_{b} C_{h}\left(T_{a}-T\right)
$$

Where $\rho_{b}$ and $C_{b}$ are the density and specific heat capacity of the blood, respectively.

Combining these two equations results in:

$$
d^{2} T /_{d x^{2}}+\left(q_{m}+W \rho_{b} C_{h}\right)\left(T_{a}-T\right) /_{k}=0
$$

Which is the Pennes Bioheat Equation for one-dimensional, steady-state, heat transfer.

He et al. studied the influence of blood flow rate on body temperature by means of a one-dimensional thermo-fluid model. This model has been recently developed for the circulation system of the upper limb and involves arteries, capillaries, and veins based on the structured-tree arterial model [61]. He concluded that his model can predict the influence of the blood flow rate and the blood pressure, as well as that of the crosssectional area on the blood temperature [62]. Craciunescu et al. studied the effect of blood velocity pulsations on bio-heat transfer. A simple model of a straight rigid blood vessel with unsteady periodic flow is considered. A numerical solution that considers the fully coupled Navier Stokes and energy equations is used for the simulations. The velocity profiles are well documented in different references that include both analytical and numerical approaches for solving for the velocity field [63, 64]. The influence of the pulsation rate on the temperature distribution and energy transport was studied for four typical vessel sizes: aorta, large arteries, terminal arterial branches, and arterioles. The results showed that the pulsating axial velocity produces a pulsating temperature distribution; reversal of flow occurs in the aorta and in large vessels, which produces significant time variation in the temperature profile. There is a small difference between the time-averaged unsteady heat flux due to a pulsating blood velocity and an assumed non-pulsating blood velocity, it is reasonable to assume a non-pulsating blood velocity for the purposes of estimating bio-heat transfer [65]. Chakravarty et al. investigated a mathematical model representing the dynamic response of heat and mass transfer to blood streaming through the arteries under stenotic conditions. The blood was treated to be a generalized Newtonian fluid and the arterial wall was considered to be rigid having differently shaped stenosis in its lumen arising from various types of abnormal growth or plaque formation. The nonlinear unsteady pulsatile flow phenomenon unaffected by the concentration-field of the macromolecules is governed by the Navier-Stokes equations together with the equation of continuity while those of the heat and the mass transfers are controlled by the heat conduction and the convection-diffusion equations, respectively. This study records that the patterns of the flow, the heat and the mass transfer, the pressure drop, the wall shear stress and the Sherwood number $\left(\mathrm{Sh}_{\mathrm{D}}\right)$ number were strongly dependent on the shape of the stenosis in addition to the non-Newtonian rheology of blood in general, and the irregular shape having closer physiological relevance, in particular. Numerical computation of the desired quantities having major physiological significance is primarily based upon the following parameters obtained from [66, 67]:

$\alpha=2, \operatorname{Re}=300, \operatorname{Pr}=0.72$,

$\mathrm{Sc}=3, \mathrm{k}=0.1, \lambda=40, \Lambda=50, \mathrm{r}_{\mathrm{o}}=0.154 \mathrm{~cm}, \rho=1.05 \times 10^{3} \mathrm{~kg} \cdot \mathrm{m}^{-3}$ and $\mathrm{L}=43.6$ 
While the results of Fig. 4 at $\mathrm{Re}=300$ represent the qualitative measure of the effect of Womersley parameter on the temperature profiles for a moderate irregular stenosis with $48 \%$ area reduction, the profiles of Fig. 5 for exhibit how they are being influenced significantly by the non-Newtonian rheology of the streaming blood. The combined effect of heat and mass transfer on non-Newtonian idealization of the streaming blood indicates a gateway to draw linkage to atherosclerosis [68].

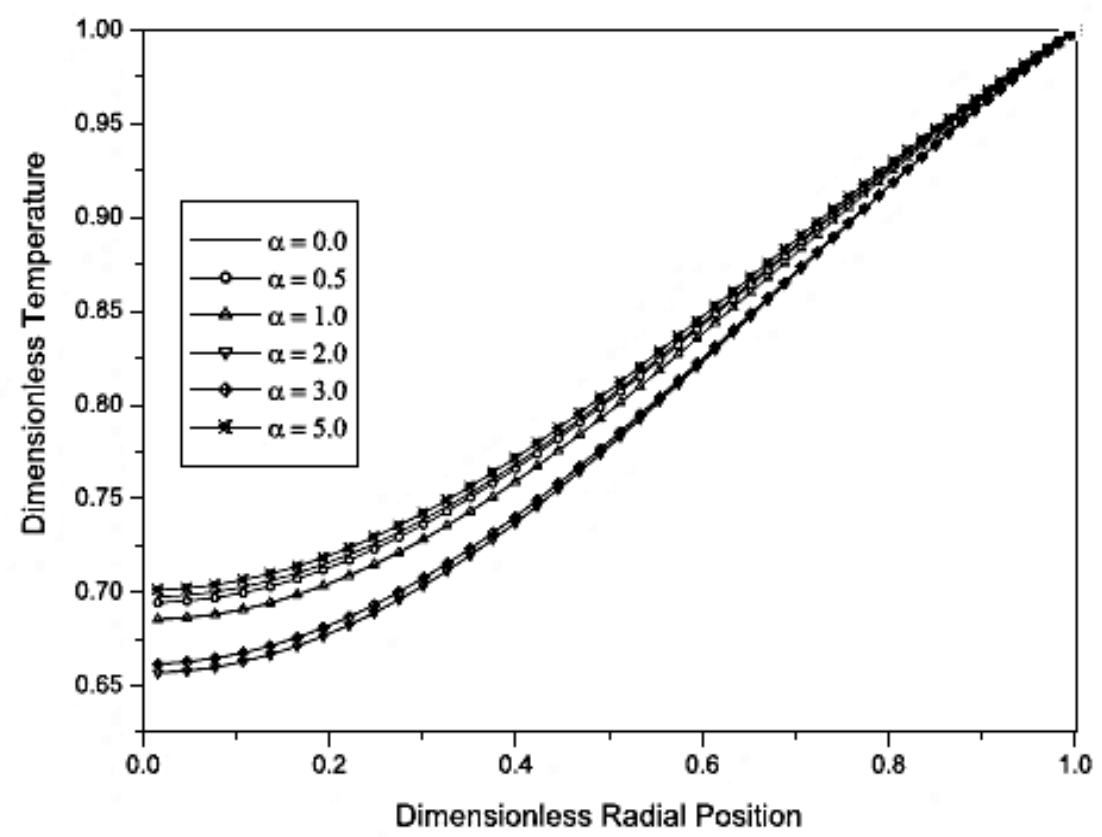

Fig. 4: Profiles of the temperature for irregular stenosis with $\mathrm{k}=0.1 \%$ and $48 \%$ area reduction at $\mathrm{Re}=300$ [68].

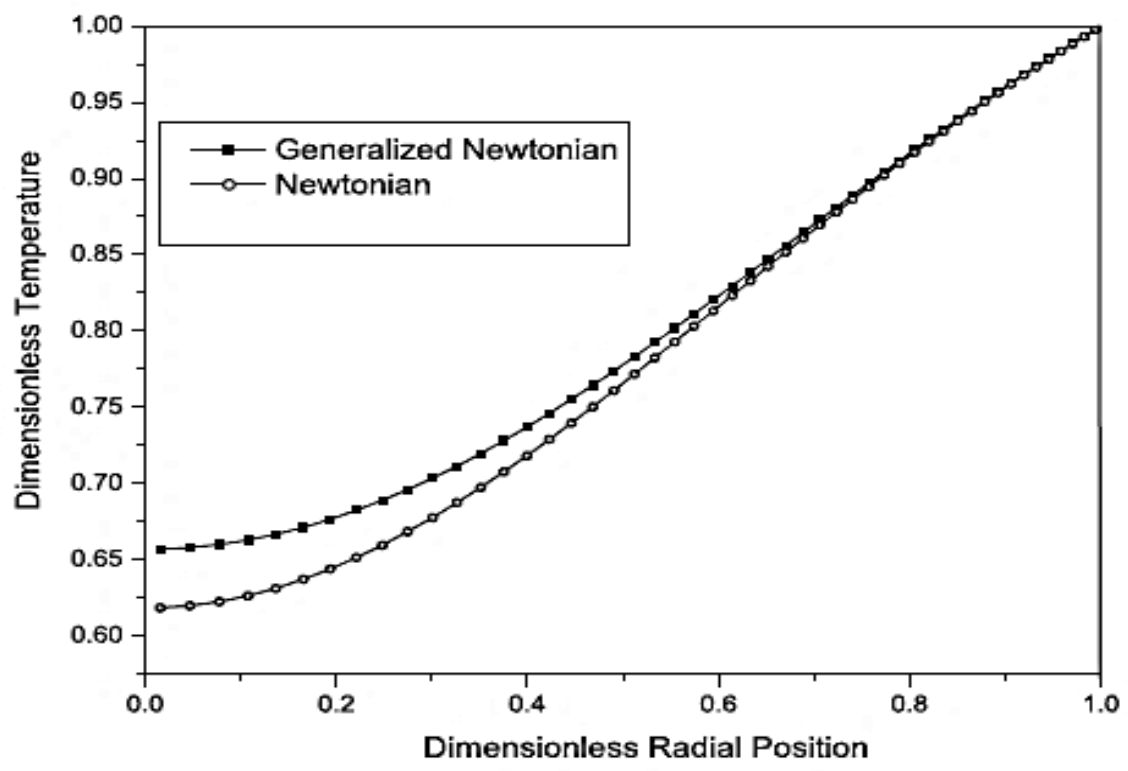

Fig. 5: Profiles of the temperature for irregular stenosis with $48 \%$ area reduction for $\mathrm{k}$ $=0.1$ and $\mathrm{a}=2$ at $\operatorname{Re}=300$ [68]. 
Ahmad et al. investigated the mathematical solution of unsteady, viscous, incompressible, electrically conducting blood flow and heat transfer through a parallel plate channel when the lower plate is stretching. The effects of flow parameters namely Grashof number $\left(\mathrm{G}_{\mathrm{r}}\right)$, Prandtl number $\left(\mathrm{P}_{\mathrm{r}}\right)$, heat source parameter $(\mathrm{N})$, Hartmann number (M) and decay parameter $(\chi)$ on the velocity and heat functions have been observed. The mathematical analysis and graphical presentations of velocity and temperature distributions are very simple and help to understand physiological fluid dynamics. The results show that temperature field increases with increase in the values of heat source parameter $(\mathrm{N})$, Fig. 6 presents the distribution of the temperature for different values of decay parameter $(\chi)$. The temperature distribution decreases against the decay parameter ( $\chi)$. Fig. 7 shows respectively that the effect of Grashof number $\left(G_{r}\right)$, Prandtl number $\left(P_{r}\right)$, and heat source parameter $(\mathrm{N})$ on the axial velocity. It is noticed that velocity increases with an increase in the values of these parameters [69].

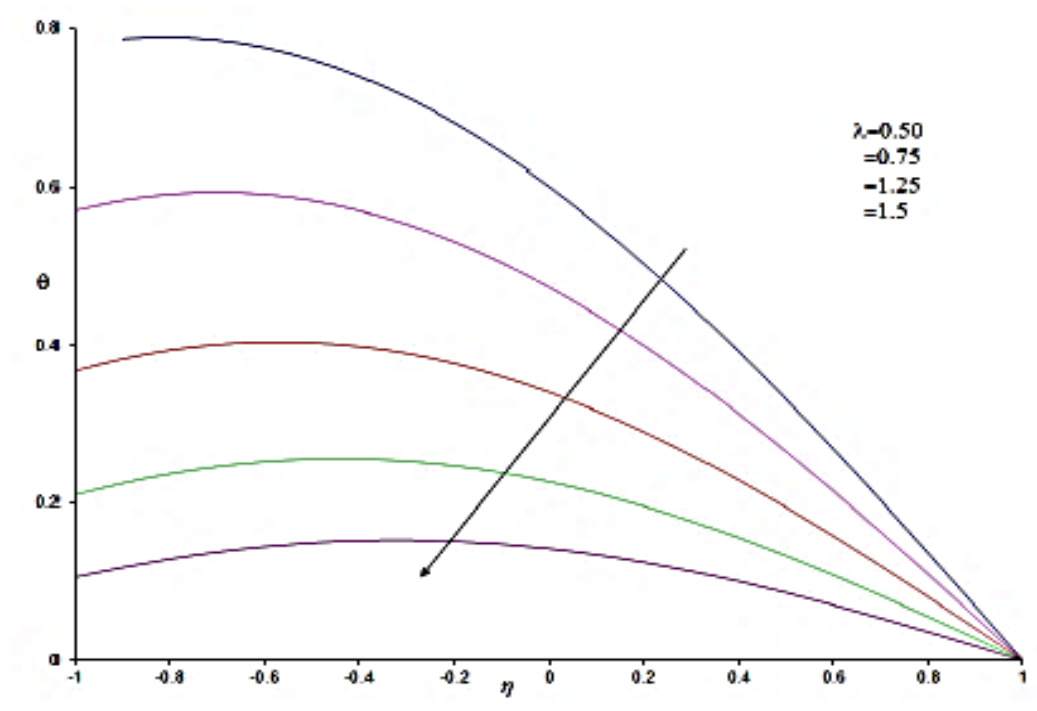

Fig. 6: Graph of temperature distribution for different values of decay parameter $(\chi)$ [69].

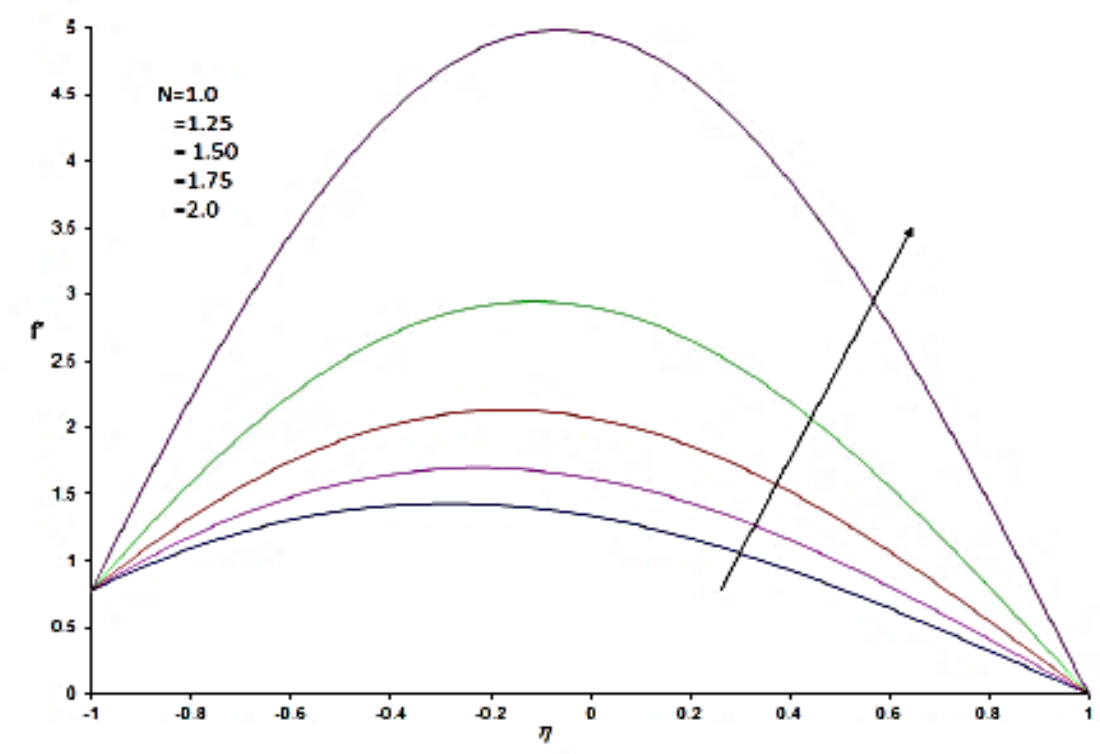

Fig. 7: Graph of axial velocity for different values of heat source parameter (N) [69]. 


\section{CONCLUSION}

In this paper, rheological characteristics of blood were studied. As referred to in previous work, blood is a complex fluid with non-Newtonian characteristics. It often represents a yield stress (viscoplasticity) and has a shear-thinning behavior and due to the pulsative nature of the blood flow, it shows a thixotropy treatment. Blood has four main determinants including plasma viscosity, hematocrit, red blood cell deformability, and temperature. Blood shows a Newtonian fluid's character when it flows through larger diameter arteries at high shear rates, but it exhibits a remarkable non-Newtonian behavior when it flows through small diameter arteries at low shear rates. Despite the fact that thixotropy is a transient property, due to the pulsative nature of the blood flow the thixotropic effects may have long term impact on the blood circulation. It should be remarked that time dependent effects whether thixotropic or viscoelastic in nature, should be expected in blood flow due to the pulsatility of blood flow and the rapid change in the deformation conditions during blood circulation. Modeling of heat transfer in the body can be used in surgery, especially open-heart surgery, as well as in making artificial blood vessels. From a simple model of a straight rigid blood vessel with unsteady periodic flow, there is a small difference between the time-averaged unsteady heat flux due to a pulsating blood velocity and an assumed non-pulsating blood velocity, it is reasonable to assume a non-pulsating blood velocity for the purposes of estimating bioheat transfer. The heat and the mass transfer, the wall shear stress and the Sherwood number $\left(\mathrm{Sh}_{\mathrm{D}}\right)$ number are strongly dependent on the shape of the stenosis in addition to the non-Newtonian rheology of blood in general.

\section{FUTURE WORK}

- Rheological models of blood flow

- Numerical simulation of the non-Newtonian blood flow

- Effects of temperature on blood viscosity

\section{REFERENCES}

[1] Da Silva JL, Rao, MA. (2007) Rheological behavior of food gels. In Rheology of Fluid and Semisolid Foods (pp. 339-401). Springer US.

[2] Kordani, N., \& Vanini, A. S. (2014) Optimizing the ethanol content of shear thickening fluid/fabric composites under impact loading. Journal of Mechanical Science and Technology, 28(2):663-667.

[3] Edward, R. (1969) Merrill, Rheology of Blood. Physiological reviews, 49(4):30-43.

[4] Cokelet GR, Merrill EW, Gilliland ER, Shin H, Britten A, Wells Jr RE. (1963) The rheology of human blood-measurement near and at zero shear rate. Transactions of the Society of Rheology, 7(1):303-317.

[5] Merrill EW, Gilliland ER, Lee TS, Salzman EW. (1966) Blood rheology: effect of fibrinogen deduced by addition. Circulation Research, 18(4):437-446.

[6] Merrill EW, Cheng CS, Pelletier GA. (1969) Yield stress of normal human blood as a function of endogenous fibrinogen. Journal of Applied Physiology, 26(1):1-3.

[7] Dintenfass L. (1962) Thixotropy of blood and proneness to thrombus formation. Circulation Research, 11(2):233-239.

[8] Merrill EW, Pelletier GA. (1967) Viscosity of human blood: transition from Newtonian to non-Newtonian. Journal of Applied Physiology, 23(2):178-182. 
[9] Chien S, Usami S, Taylor HM, Lundberg JL, Gregersen MI. (1966) Effects of hematocrit and plasma proteins on human blood rheology at low shear rates. Journal of Applied Physiology, 21(1):81-87.

[10] Picart C, Piau JM, Galliard H, Carpentier P. (1998) Human blood shear yield stress and its hematocrit dependence. Journal of Rheology, 42(1):1-12.

[11] Dintenfass L. (1962) Thixotropy of blood and proneness to thrombus formation. Circulation Research, 11(2):233-239.

[12] Sochi T. (2010) Flow of non-Newtonian fluids in porous media. Journal of Polymer Science Part B: Polymer Physics, 48(23):2437-2767.

[13] Davenport, P., \& Roath, S. (1981) Blood thixotropy. Journal of clinical pathology, 34(1):106-117.

[14] Mandal P K. (2005) An unsteady analysis of non-Newtonian blood flow through tapered arteries with a stenosis. International Journal of Non-Linear Mechanics, 40(1):151-164.

[15] Fung YC. (1993) Biomechanics-Mechanical Properties of Living Tissues, 2nd edn.

[16] Guyton AC, Hall JE. (1996) Textbook of Medical Physiology, 9th edition, W.B. Sanders Company, Philadelphia.

[17] Dinnar U. (1981) Cardiovascular fluid dynamics. CRC Press, Boca Raton, FL.

[18] Chien S, Dormandy JA, Ernst E, Matrai, A. (2012) Clinical hemorheology: Applications in cardiovascular and hematological disease, diabetes, surgery and gynecology (vol. 74). Springer Science \& Business Media.

[19] Cheng DC, Evans F. (1965) Phenomenological characterization of the rheological behaviour of inelastic reversible thixotropic and antithixotropic fluids. British Journal of Applied Physics, 16(11):1599-1614.

[20] Mewis J, Spaull AJB. (1976). Rheology of concentrated dispersions. Advances in Colloid and interface Science, 6(3):173-200.

[21] Nakamura M, Sawada T. (1988) Numerical study on the flow of a non-Newtonian fluid through an axisymmetric stenosis. Journal of Biomechanical Engineering, 110(2):137-143.

[22] Stoltz JF, Singh M, Riha P. (1999) Hemorheology in practice (vol. 30). IOS press.

[23] Barbee JH. (1973) The effect of temperature on the relative viscosity of human blood. Biorheology, 10(1):1-5.

[24] Cokelet GR. (1972) The rheology of human blood. Biomechanics: its foundations and objectives, 72:63-103.

[25] Rathod VP, Tanveer S. (2009) Pulsatile flow of couple stress fluid through a porous medium with periodic body acceleration and magnetic field. Bulletin of the Malaysian Mathematical Sciences Society, 32(2):245-259.

[26] Boyd W. (1964) A Text-book of Pathology: Structure and Function in Diseases. Lea \& Febiger: Philadelphia. pp. 130-133.

[27] Chandran KB, Rittgers SE, Yoganathan AP. (2012) Biofluid mechanics: the human circulation. CRC press.

[28] Blair GS. (1959) An equation for the flow of blood, plasma and serum through glass capillaries. Nature, 183(4661):613-614.

[29] Copley AL. (1960) Apparent viscosity and wall adherence of blood systems. Flow properties of blood and other biological systems, Pergamon Press, Oxford, UK, p. 97.

[30] Casson N. (1959) A flow equation for pigment-oil suspensions of the printing ink type. In:Mill CC, editor. Rheology of disperse systems. New York: Pergamon Press. pp. 82-104.

[31] Venkatesan J, Sankar DS, Hemalatha K, Yatim, Y. (2013) Mathematical analysis of Casson fluid model for blood rheology in stenosed narrow arteries. Journal of Applied Mathematics, 2013, pp. 1-11.

[32] Misra JC, Shit GC. (2006) Blood flow through arteries in a pathological state: A theoretical study. International Journal of Engineering Science, 44(10):662-671.

[33] Bodnár T, Sequeira A, Prosi M. (2011) On the shear-thinning and viscoelastic effects of blood flow under various flow rates. Applied Mathematics and Computation, 217(11):50555067. 
[34] Fisher C, Rossmann J S. (2009) Effect of non-Newtonian behavior on hemodynamics of cerebral aneurysms. Journal of biomechanical engineering, 131(9):091004.

[35] Replogle RL, Meiselman HJ, Merrill EW. (1967) Clinical implications of blood rheology studies. Circulation, 36(1):148-160.

[36] Edward, R. (1969) Merrill, Rheology of Blood. Physiological reviews, 49(4):30-43.

[37] Morris CL, Rucknagel DL, Shukla R, Gruppo RA, Smith CM, Blackshear P. (1989) Evaluation of the yield stress of normal blood as a function of fibrinogen concentration and hematocrit. Microvascular research, 37(3):323-338.

[38] Lee BK, Xue S, Nam J, Lim H, Shin S. (2011) Determination of the blood viscosity and yield stress with a pressure-scanning capillary hemorheometer using constitutive models. Korea-Australia Rheology Journal, 23(1):1-6.

[39] Fedosov DA, Pan W, Caswell B, Gompper G, Karniadakis GE. (2011) Predicting human blood viscosity in silico. Proceedings of the National Academy of Sciences, 108(29):1177211777.

[40] Barnes HA. (1997) Thixotropy—a review. Journal of Non-Newtonian fluid mechanics, $70(1): 1-33$

[41] How TV. (ed.). (1996). Advances in Hemodynamics and Hemorheology (vol. 1). Elsevier.

[42] Huang CR, Siskovic N, Robertson RW, Fabisiak W, Smitherberg EH, Copley AL. (1975) Quantitative characterization of thixotropy of whole human blood. Biorheology, 12(5):279282.

[43] Gaspar-Rosas A, Thurston GB. (1988) Erythrocyte aggregate rheology by transmitted and reflected light. Biorheology, 25(3):471-487.

[44] Pop GAM, Duncker DJ, Gardien M, Vranckx P, Versluis S, Hasan D, Slager CJ. (2002) The clinical significance of whole blood viscosity in (cardio) vascular medicine. Netherlands Heart Journal, 10(12):512-524.

[45] Cho YI, Cho DJ, Rosenson RS. (2014) Endothelial shear stress and blood viscosity in peripheral arterial disease. Current atherosclerosis reports, 16(4):404-419.

[46] Grotta J, Ackerman R Correia J, Fallick G, Chang J. (1982) Whole blood viscosity parameters and cerebral blood flow. Stroke, 13(3):296-301.

[47] Brown M, Marshall J. (1985) Regulation of cerebral blood flow in response to changes in blood viscosity. The Lancet, 325(8429):604-609.

[48] Tanner RI. (1985) Engineering Rheology, Clarendon. Oxford, 15, pp. 355-370.

[49] Ferguson J, Kemblowski Z. (1991) Applied Fluid Rheology, Elsevier, London, pp. 47-115.

[50] Macosko CW. (1994) Rheology: principles, measurements, and applications. VHC Publishers Inc., New York.

[51] Rosencranz R, Bogen SA. (2006) Clinical laboratory measurement of serum, plasma, and blood viscosity. Pathology Patterns Reviews, 125(suppl-1): S78-S86.

[52] Shin S, Keum DY, Ku YH. (2002) Blood viscosity measurements using a pressure-scanning capillary viscometer. Journal of Mechanical Science and Technology, 16(12):1719-1724.

[53] Shin S, Hou JX, Suh JS, Singh M. (2007) Validation and application of a microfluidic ektacytometer (RheoScan-D) in measuring erythrocyte deformability. Clinical hemorheology and microcirculation, 37(4):319-328.

[54] Lee BK, Xue S, Nam J, Lim H, Shin S. (2011). Determination of the blood viscosity and yield stress with a pressure-scanning capillary hemorheometer using constitutive models. Korea-Australia Rheology Journal, 23(1):1-6.

[55] Jun Kang Y, Yeom E, Lee SJ. (2013) A microfluidic device for simultaneous measurement of viscosity and flow rate of blood in a complex fluidic network. Biomicrofluidics, 7(5):054111.

[56] Kang D, Wang W, Lee J, Tai YC, Hsiai TK. (2015, June) Measurement of viscosity of adult zebrafish blood using a capillary pressure-driven viscometer. In Solid-State Sensors, Actuators and Microsystems (Transducers), 2015 Transducers-2015 18th International Conference on (pp. 1661-1664). IEEE.

[57] Nemeth N, Alexy T, Furka A, Baskurt OK, Meiselman HJ, Furka I, Miko I. (2009) Interspecies differences in hematocrit to blood viscosity ratio. Biorheology, 46(2):155-165. 
[58] Furukawa K, Abumiya T, Sakai K, Hirano M, Osanai T, Shichinohe H, Houkin K. (2016) Measurement of human blood viscosity by an electromagnetic spinning sphere viscometer. Journal of medical engineering \& technology, 40(6):285-292.

[59] Pennes HH. (1948) Analysis of tissue and arterial blood temperatures in the resting human forearm. Journal of applied physiology, 1(2):93-122.

[60] Incropera FP. (2007) Introduction to Heat Transfer, 5th ed. John Wiley and Sons Inc., New York, NY, 581-619.

[61] Olufsen MS, Peskin CS, Kim WY, Pedersen EM, Nadim A, Larsen J. (2000) Numerical simulation and experimental validation of blood flow in arteries with structured-tree outflow conditions. Annals of biomedical engineering, 28(11):1281-1299.

[62] He Y, Liu H, Himeno R. (2004) A one-dimensional thermo-fluid model of blood circulation in the human upper limb. International Journal of Heat and Mass Transfer, 47(12):27352745.

[63] Atabek HB, Chang CC. (1961) Oscillatory flow near the entry of a circular tube. Zeitschrift für Angewandte Mathematik und Physik (ZAMP), 12(3):185-201.

[64] Ling SC, Atabek HB. (1972) A nonlinear analysis of pulsatile flow in arteries. Journal of Fluid Mechanics, 55(3):493-511.

[65] Craciunescu OI, Clegg ST. (2001) Pulsatile blood flow effects on temperature distribution and heat transfer in rigid vessels. Transaction-American Society of Mechanical Engineers Journal of Biomechanical Engineering, 123(5):500-505.

[66] Back LH, Cho YI, Crawford DW, Cuffel RF. (1984) Effect of mild atherosclerosis on flow resistance in a coronary artery casting of man. Journal of biomechanical engineering, 106(1):48-53.

[67] Milnor WR. (1992) Hemodynamics, Baltimore: Williams and Williams, p. 20.

[68] Chakravarty S, Mandal PK. (2009) Effect of heat and mass transfer on non-Newtonian flowLinks to atherosclerosis. International Journal of Heat and Mass Transfer, 52(25):5719-5730.

[69] Ahmad, F., Hussain, S., \& Ansari, A. (2015) Unsteady MHD blood flow with micropolar fluid characteristics and heat source through parallel plate channel. Journal of Applied Environment \& Biological Sciences, 5(4):80-86. 